\title{
International Sports Law Journal (2016) 16:3-4
}

\author{
Johan Lindholm ${ }^{1}$
}

Published online: 12 April 2017

(C) T.M.C. Asser Instituut 2017

It is an honour to take over as Editor-in-Chief for the International Sports Law Journal with this, the journal's seventeenth volume. Since it was launched, the International Sports Law Journal has contributed greatly to the advancement of the field of international sports law by connecting sports law academics and practitioners separated by distance and culture and by serving as an international source of information about the development of sports law. For example, after getting my doctorate in European and Comparative Law, I came across an article in the journal (Soek 2002) that inspired me to initiate a research project studying the interface between law and sports in combating doping and that launched my research career in sports law in earnest. I am very happy for this opportunity to help produce a journal that will hopefully inspire others to participate in the fascinating field of international sports law.

It is my distinct privilege to introduce the International Sports Law Journal's new Editorial Board consisting of Antoine Duval (Asser International Sports Law Centre), Borja García (Loughborough University), Mark James (Manchester Metropolitan University), Dionne Koller (University of Baltimore Law School), Despina Mavromati (the Court of Arbitration for Sport), Richard Parrish (Edge Hill University), Ryan Rodenberg (Florida State University) and Ben Van Rompuy (Universiteit Leiden). International sports law is a rapidly expanding field where new issues continuously arise. The Editorial Board has been carefully selected to cover as much of the field as possible.

Johan Lindholm

johan.lindholm@umu.se

1 Department of Law, Umeå University, 90187 Umeå, Sweden
The Editorial Board and I want to thank outgoing Editor-in-Chief Jack Anderson and the previous Editorial Board for all the effort that they have invested in making the International Sports Law Journal the premiere journal for international sports law. They have generously offered to stay on the journal's Advisory Board, and for this we are truly grateful. We on the editorial team will do our utmost to try to fill their shoes.

We will work hard to maintain the journal's relevance to a broad audience and invite academics and practitioners to submit contributions on all subjects that relate to law and sports. We also welcome organisers of sports law conferences, seminars and workshops to submit proposals for special issues or sections of the ISLJ. Because we want to ensure and strengthen the journal's international nature, we particularly hope to receive contributions addressing sports law issues relating to Asia, Africa and South America.

On October 26-27, 2017, the International Sports Law Journal will host its First Annual Conference on International Sports Law. The conference, which is organised with the generous support of the ASSER Institute, will be taking place in The Hague. Keynote speakers will include Richard McLaren, Stephen Weatherill and Miguel Maduro. We encourage practitioners and researchers at all stages of their careers to submit abstracts by May 15. More information about the conference and the call for papers will be found on the ASSER Institute's website.

The articles published in this issue, four of which concern different aspects of maintaining the integrity of sport, show the breadth and importance of international sports law. In his article, Antoine Duval addresses the Russian doping scandal that truly shook the international sports world in connection with the 2016 Rio Summer Games when Russian athletes were barred from participating. This gave rise to several cases before the Court of Arbitration 
for Sport which has issued a number of awards with connection to the scandal. Duval presents these awards and their consequences for the international fight against doping going forward. Claire Summer's article also concerns how anti-doping systems can be improved. Focusing on the legal situation in the United Kingdom, Summer argues that criminalising doping would support fair-play and equality in sport by increasing the cost of doping and enhancing the 'spirit of sport'. Doping is also a central issue in Jonathan Glen Merritt's article that more generally addresses regulatory options for equestrian sports. Departing from some of the controversies affecting equestrian sports, the author points to particular problems arising from the current application of doping rules to equestrianism and proposes regulatory changes. Finally and on a similar theme, Salomeja Zaksaitè and Karolis Raduševičius in their article address the present use of 'manipulative practices' in Formula 1 and how to best identify and discourage practices that constitute cheating.

A second set of articles in this issue focuses on the more commercial aspects of international sports law. Oskar van Maren analyses and compares the EU Commission's recent decisions on when public financial support to local football clubs constitutes state aid banned under European Union law. The author analyses and compares the decisions regarding aid to Dutch clubs, which the Commission found to be in compliance with Union law, and aid to Spanish clubs, which the Commission found constituted unlawful state aid. The Spanish clubs have appealed the latter decisions to the European Union's courts. ${ }^{1}$ In his article, Paolo Garraffa discusses the protection of sports-related trademarks in China, drawing lessons from American basketball superstar Michael Jordan's unsuccessful litigation against a Chinese company that had registered and used several trademarks associated with him. Finally, Terrence D. Brennan discusses problems with enforcement of rules governing training compensation and solidarity contributions in football. These mechanisms seek to ensure that clubs that develop players are financially compensated - and thereby also incentivised to develop playersif they leave for other clubs. The author highlights and criticises the responsible American sport governing bodies' failure to enforce the applicable FIFA rules.

Finally, Mordehai Mironi examines the advantages and shortcoming of mediation as a means for dispute resolution in sport. Arbitration has developed into a new way to resolve sports-related disputes. In his article, Mironi points out that mediations have certain advantages compared to arbitration and that experiences with using mediation in sports are encouraging.

\section{Reference}

Soek J (2002) The legal nature of doping law. Int Sports Law J 2

$\overline{1}$ Cases T-845/16 and T-846/16. 